\title{
Modified arthroscopic Broström procedure using a soft anchor for chronic lateral ankle instability: Short-term follow-up results
}

\author{
Ramin Moradi, $\mathrm{MD}^{1}$ (D), Bertan Cengiz, $\mathrm{MD}^{2}$ (D) \\ ${ }^{1}$ Department of Orthopedics and Traumatology, Private Sincan Koru Hospital, Ankara, Turkey \\ ${ }^{2}$ Department of Orthopedics and Traumatology, Acıbadem Kayseri Hospital, Kayseri, Turkey
}

Ankle sprain is the most common lower extremity injury in sports, and lateral ankle sprains constitute the majority of ankle sprains. ${ }^{[1]}$ The mechanism of injury involves an inversion force applied on the foot while in plantar flexion. This type of trauma may cause damage to the lateral collateral ligament complex (anterior talofibular ligament [ATFL], calcaneofibular ligament [CFL], posterior talofibular ligament [PTFL]). ${ }^{[2]}$ Many patients receive conservative treatment, but recurrence is common. ${ }^{[3]}$ Nearly one-third of patients with lateral ankle sprain develop chronic ankle instability (CAI) characterized by the persistence of instability for six months after initial trauma. ${ }^{[4]}$ In patients with CAI, ATFL is almost always present, either solitarily (per se) or coexisting with CFL injury. ${ }^{[5-7]}$

Ligament tear is observed in addition to pathological hypermobility detected in the tibiotalar

Received: December 31, 2020

Accepted: April 15, 2021

Published online: November 19, 2021

Correspondence: Ramin Moradi, MD. Özel Sincan Koru Hastanesi Ortopedi ve Travmatoloji Bölümü, 06934 Sincan, Ankara, Türkiye.

E-mail: dr_r_moradi@yahoo.com

Doi: $10.52312 /$ jdrs.2021.34

Citation: Moradi R, Cengiz B. Modified arthroscopic Broström procedure using a soft anchor for chronic lateral ankle instability: Short-term follow-up results. Jt Dis Relat Surg 2021;32(3):744-751.

(O2021 All right reserved by the Turkish Joint Diseases Foundation

This is an open access article under the terms of the Creative Commons Attribution-NonCommercial License, which permits use, distribution and reproduction in any medium, provided the original work is properly cited and is not used for commercial purposes (http://creativecommons.org/licenses/by-nc/4.0/).

\section{ABSTRACT}

Objectives: This study aims to examine the clinical outcomes and complications of lateral ligament reconstruction performed using soft anchors according to the arthroscopic modified Broström technique (MBT) for the treatment of chronic ankle instability (CAI) and to evaluate the frequency of return to sports.

Patients and methods: A total of 14 patients with CAI ( 9 males, 5 females; mean age: $30.1 \pm 4.6$ years; range, 22 to 38 years) who underwent the MBT with soft anchors between January 2015 and December 2019 were retrospectively analyzed. Ankle function was evaluated using the American Orthopaedic Foot \& Ankle Society (AOFAS) Ankle-Hindfoot Scale and Karlsson Ankle Function Score (Karlsson/Peterson, K/D score), while pain was evaluated using the Visual Analog Scale (VAS) after a minimum follow-up of 12 months.

Results: The mean follow-up was $23.6 \pm 7.7$ months. The mean overall AOFAS score was $74.0 \pm 2.6$ preoperatively, which improved to $96.2 \pm 1.9$ in the postoperative period $(\mathrm{p}=0.001)$. The mean pre- and postoperative $\mathrm{K} / \mathrm{P}$ scores were $72.4 \pm 3.1$ (range, 68 to 78 ) and $95.3 \pm 2.2$ (range, 92 to 98 ), respectively ( $p=0.001$ ). The mean preoperative VAS score was $2.4 \pm 0.9$ (range, 1 to 4 ) and showed a significant improvement to $0.6 \pm 0.5$ (range, 0 to 1 ) in the postoperative period $(\mathrm{p}=0.001)$. Nine $(64.3 \%)$ patients returned to sports activities after surgery at a mean period of $9 \pm 2.1$ months.

Conclusion: In the treatment of CAI, arthroscopic MBT performed with soft anchors provides successful outcomes in short-term follow-up. In addition to being a minimally invasive technique, MBT is a reliable and safe approach with low complication rates and significant functional improvement. However, the low ratio of return to sports should be considered as a failure of this technique.

Keywords: Ankle instability, arthroscopic reconstruction, lateral ankle ligaments, soft anchor.

joint in patients who exhibit signs of mechanical instability. Moreover, patients who have signs of functional instability may experience problems associated with ankle sprain, as well as more subjective findings due to the increased proprioception-without 
any radiological pathologies. ${ }^{[8]}$ Due to the high possibility for adverse consequences resulting from CAI itself and instability-related risks, ${ }^{\left[{ }^{[9]}\right.}$ surgical treatment should be considered, unless satisfactory functional outcomes and stability can be ensured with conservative treatment.

The open modified Broström technique (MBT), which is commonly preferred in lateral ankle instability, has been used for anatomic reconstruction ${ }^{[10]}$ with successful functional outcomes. ${ }^{[11,12]}$ However, isolated lateral ligament repair performed with this technique has been shown to result in poor clinical outcomes in the presence of coexisting intraarticular pathologies that are not treated in the same session. ${ }^{[13,14]}$ In addition, it has been suggested that some intraarticular pathologies cannot be visualized with preoperative magnetic resonance imaging (MRI) ${ }^{[13,15,16]}$ and priority should be given to arthroscopic evaluation in such treatment procedures. ${ }^{[13,17-19]}$ Good clinical outcomes compared to open surgery have been reported in many previous studies. ${ }^{[10,20-22]}$ However, complication rates due to the anchor use are also known to be high. ${ }^{[23]}$

In the present study, we aimed to examine the clinical outcomes and complications of lateral ligament reconstruction performed using soft anchors according to the arthroscopic MBT for the treatment of CAI and to evaluate the frequency of return to sports activities.

\section{PATIENTS AND METHODS}

This single-centre, retrospective study was conducted at Private Sincan Koru Hospital, Department of Orthopedics and Traumatology between January 2015 and December 2019. A total of 14 patients with CAI ( 9 males, 5 females; mean age: $30.1 \pm 4.6$ years; range, 22 to 38 years) who underwent the MBT for full-thickness ATFL rupture with soft anchors were included. All procedures were performed by a single surgeon. Exclusion criteria were as follows: presence of an evident bone deformity, neuromuscular disorders, general joint laxity, and augmented ATFL reconstruction with tendons. A written informed consent was obtained from each patient. The study protocol was approved by the Acibadem University Ethics Committee (No: 2020-19/26; Date: 03.09.2020). The study was conducted in accordance with the principles of the Declaration of Helsinki.

There was at least one inversion injury of the ankle in all patients. All patients continued to complain of instability after at least six months of conservative treatment. Based on the clinical examinations, every patient had a positive anterior drawer and talar tilt test. Preoperative standard anteroposterior, lateral and varus stress radiographs and MRIs of the ankles were obtained. The MRI studies revealed that all patients had a complete or partial CFL lesion in addition to a complete ATFL lesion.

All scoring and assessments at pre- and postoperative time points were performed by the same observer. The examination consisted of pre- and postoperative Visual Analog Scale (VAS), American Orthopaedic Foot \& Ankle Society (AOFAS) Ankle-Hindfoot Scale, and Karlsson/Peterson (K/P) scores. For all patients, thorough surgical data and intraoperative findings recorded during surgery were documented. All patients with CAI were followed for at least 12 months after surgery. Preoperative assessments were performed and recorded one week before surgery, and postoperative assessments were recorded at the last follow-up investigation of each patient.

\section{Surgical technique}

Routine anterior ankle arthroscopy portals are used in this technique. However, the anterolateral portal is placed at nearly $1 \mathrm{~cm}$ to the anterior of the lateral malleolus, at the normal superior border of the ATFL. At the initial stage, diagnostic arthroscopy is used to evaluate the ATFL and if a tear is detected, debridement is performed at the attachment of the fibula with a shaver to reveal the footprint of the ligament. During diagnostic arthroscopy, the intraarticular lesions are evaluated and figured out, This is followed by placing a four-thread soft anchor (2.9 mm JuggerKnot ${ }^{\mathrm{TM}}$, Zimmer-Biomet Orthopedics, Warsaw, Indiana, USA) perpendicular to the fibula and parallel to the fifth metatarsal into the mid-portion of the footprint area of the fibula prepared before. Then, the anchor threads are advanced through the ankle capsule and inferior extensor retinaculum at 7, 8, 9 and 10 o'clock positions on the left side and 2, 3, 4 and 5 o'clock positions on the right side 1 to $1.5 \mathrm{~cm}$ anterior to the lateral portal, with same-colored threads remaining adjacent. The threads are pulled below the skin, while they are free to check whether the lateral malleolus is covered by the inferior extensor retinaculum with a scope. Then, same-colored threads are knotted together, after which portal entries are closed, and a short leg splint is placed on the leg with the ankle fixed at 90 degrees. Controlled active and passive movements are initiated after removing the splints after a three-week recovery period. Load bearing is postponed, until the end of postoperative sixth week for the operated extremity (Figures 1-3). 


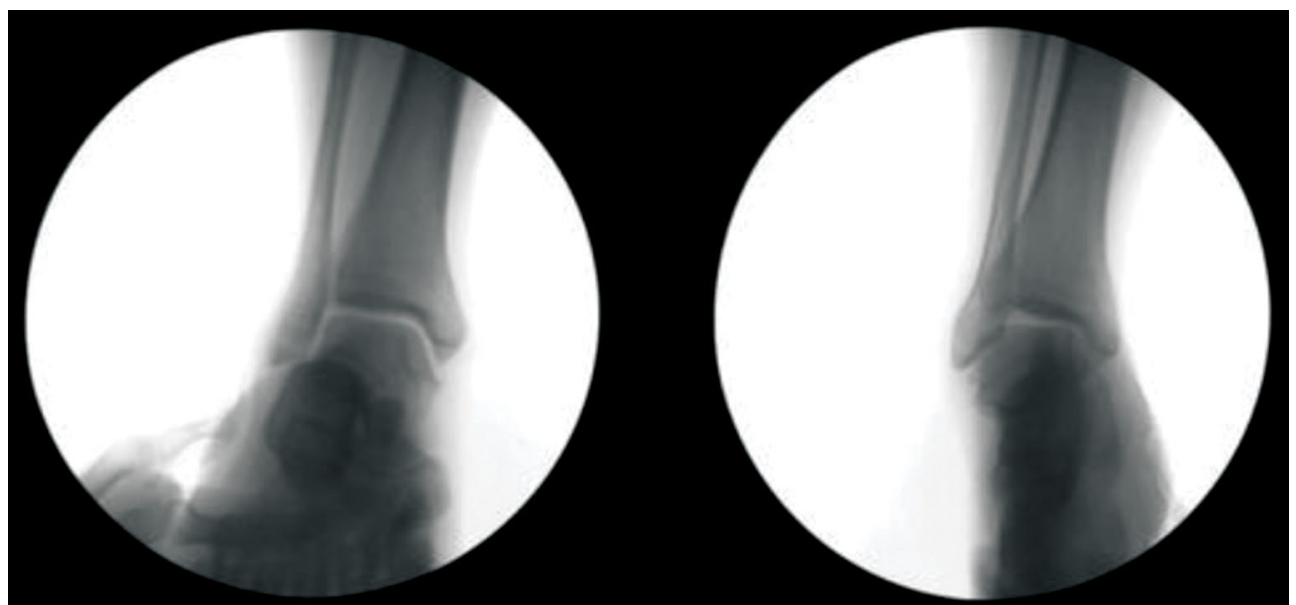

FIGURE 1. Perioperative stress radiography under fluoroscopy showing lateral opening in the ankle with varus stress.

\section{Clinical evaluation}

An experienced orthopedic surgeon conducted clinical examinations comprised of subjective functional and physical evaluations. The surgeon performing clinical evaluations was blinded to the repair procedure. The AOFAS, $\mathrm{K} / \mathrm{P}$ and VAS scores were included in the functional examination, and the physical examination included the anterior drawer test (ADT). Clinical ADT evaluation was performed for both sides: a side-to-side difference less than $5 \mathrm{~mm}$ in tibiotalar translation was considered normal (Grade 0); 5 to $10 \mathrm{~mm}$ was considered Grade 1; 10 to $15 \mathrm{~mm}$ was considered Grade 2, and higher than $15 \mathrm{~mm}$ was considered Grade 3.[17]
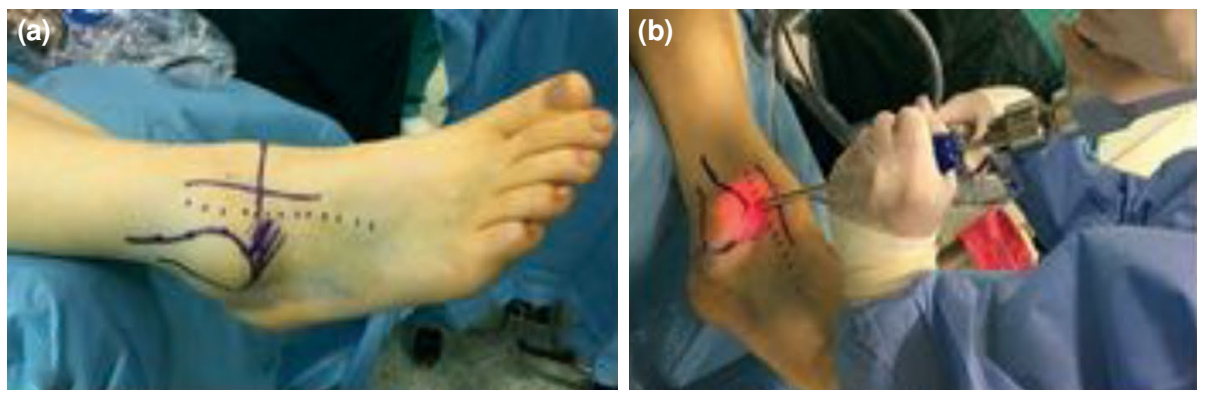

(d)
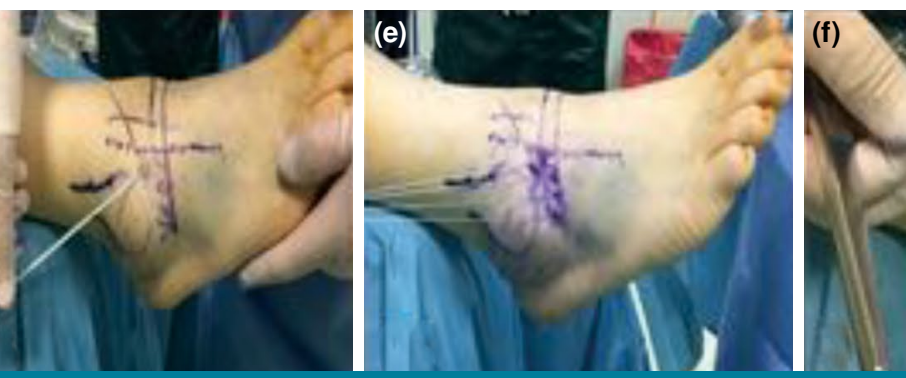

FIGURE 2. (a) Marking of the important structures of the right foot of the patient preoperatively. The patient was positioned in the supine position. Lateral and medial malleolus, tibialis anterior tendon, superficial peroneal nerve, and inferior extensor retinaculum were marked; (b) Arthroscopically, placing the soft anchor on the ruptured ATFL footprint in the fibula; (c) $2.9 \mathrm{~mm}$ soft anchor used in Modified Broström operation; (d) Checking the stability of the anchor by pulling the threads together after the anchor placement in the footprint; (e) Passing the anchor threads under the inferior extensor retinaculum in the right foot at 2, 3, 4, 5 o'clock; (f) The threads carried from the subcutaneous to the portal; (g) The same colored threads knotted together, while at the same time confirming arthroscopically that the inferior extensor retinaculum covers the footprint.

ATFL: Anterior talofibular ligament. 

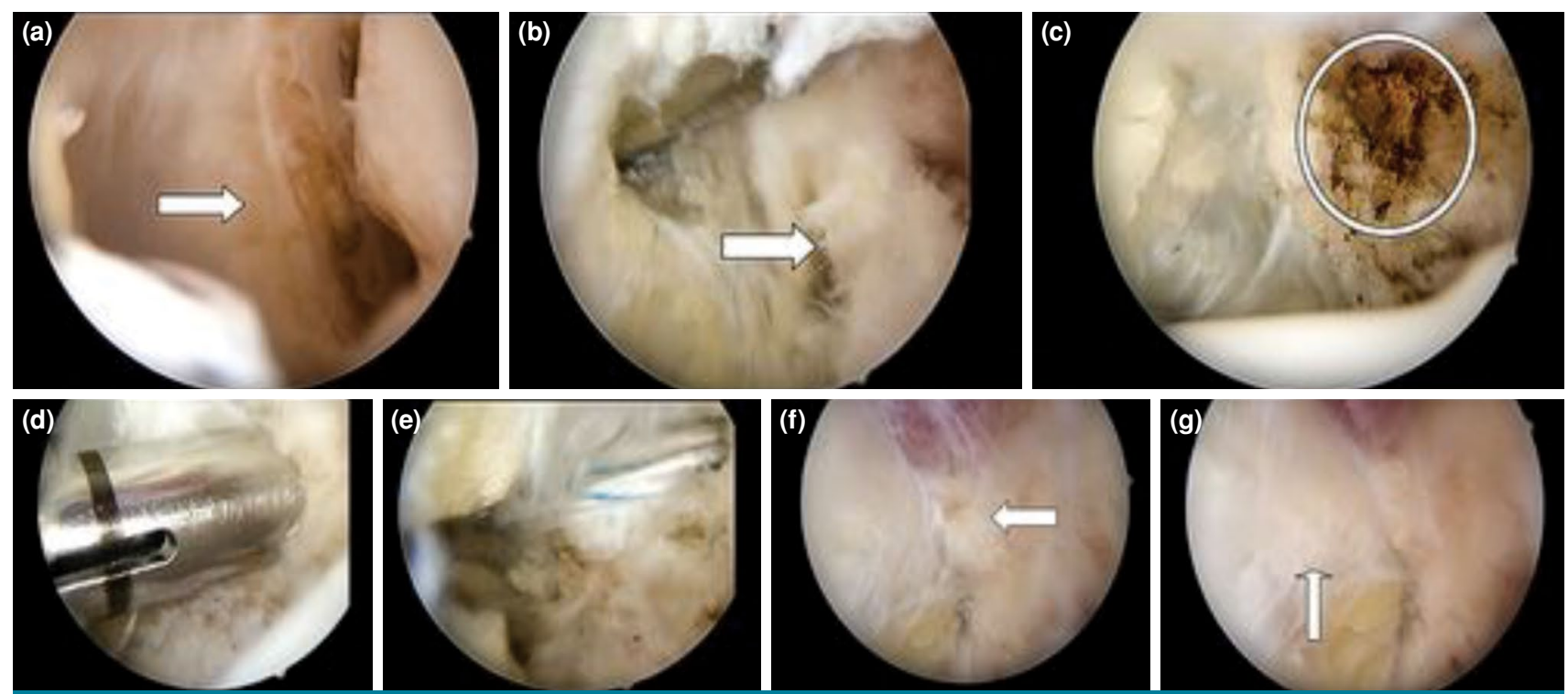

FIGURE 3. (a) Arthroscopic view from the anterolateral portal, white arrow shows the degenerated and ruptured ATFL as seen the footprint is empty; (b) Degenerated stump remaining from ATFL after debridement with shaver (white arrow); (c) The image from the anteromedial portal of the marked footprint of ATFL on the fibula after debridement; (d) Arthroscopic placement of the soft anchor in the footprint area of the fibula; (e) The appearance of the threads after placing the soft anchor in the footprint; (f, g) After the anchor suture limbs were passed through the ankle capsule and inferior extensor retinaculum and knotted, covering the footprint was checked with the scope. White arrows show the coverage of the footprint from the anterolateral portal.

ATFL: Anterior talofibular ligament.

\section{Statistical analysis}

Statistical analysis was performed using the IBM SPSS version 21.0 software (IBM Corp., Armonk, NY, USA). For the normality check, the ShapiroWilk test was used. Data were expressed in mean \pm standard deviation (SD) or median (min-max) for continuous variables and in number and frequency for categorical variables. Normally distributed variables were analyzed using the two-way repeated measures analysis of variance (ANOVA). Non-normally distributed variables were analyzed using the Wilcoxon signed-rank test for repeated measurements. Pairwise comparisons were performed with the Bonferroni correction method. A $p$ value of $<0.05$ was considered statistically significant.

\section{RESULTS}

Demographic data of the patients are summarized in Table I. The mean duration of instability symptoms after ankle trauma until surgery was $34.0 \pm 12.8$ (range, 18 to 60 ) months. The mean follow-up was $23.6 \pm 7.7$ (range, 12 to 33) months. Ankle instability was not observed in any of the patients and all ankles had normal ADT results (Grade 0) postoperatively.
Accompanying lesions were talar osteochondral lesions (OCL) in three patients ( $n=1$ Grade 1 and $n=2$ Grade 2 according to Berndt and Harty classification). In patients with Grade $2 \mathrm{OCL}$, the fringed parts were debrided with a shaver. No intervention was applied to the patient with Grade 1 OCL. These lesions had no effect on follow-up and treatment. No accompanying lesions were seen except for OCLs.

The mean overall AOFAS score was $74.0 \pm 2.6$ (range, 70 to 78 ) preoperatively, and improved to

\begin{tabular}{|c|c|c|c|}
\hline \multicolumn{4}{|c|}{$\begin{array}{c}\text { TABLE I } \\
\text { Demographic characteristics of patients }\end{array}$} \\
\hline Variable & $\mathrm{n}$ & $\%$ & Mean $\pm S D$ \\
\hline Age (year) & & & $30.1 \pm 4.6$ \\
\hline \multicolumn{4}{|l|}{ Sex } \\
\hline Male & 9 & 64.3 & \\
\hline Female & 5 & 35.7 & \\
\hline Duration of symptoms & & & $34.0 \pm 12.8$ \\
\hline Follow-up period & & & $23.6 \pm 7.7$ \\
\hline
\end{tabular}




\begin{tabular}{|c|c|c|}
\hline \multicolumn{3}{|c|}{$\begin{array}{c}\text { TABLE II } \\
\text { Comparisons of outcome scores before and after operation }\end{array}$} \\
\hline & Mean $\pm S D$ & $p$ \\
\hline AOFAS Ankle-Hindfoot Scale & & 0.001 \\
\hline Preoperative & $74.0 \pm 2.6$ & \\
\hline Postoperative & $96.2 \pm 1.9$ & \\
\hline Karlsson-Peterson & & 0.001 \\
\hline Preoperative & $72.4 \pm 3.1$ & \\
\hline Postoperative & $95.3 \pm 2.2$ & \\
\hline VAS & & 0.001 \\
\hline Preoperative & $2.4 \pm 0.9$ & \\
\hline Postoperative & $0.6 \pm 0.5$ & \\
\hline $\begin{array}{l}\text { SD: Standard deviation; AOFAS: } \\
\text { Society; VAS: Visual Analog Scale. }\end{array}$ & opaedic Fo & Ankle \\
\hline
\end{tabular}

\begin{tabular}{|c|c|c|c|c|}
\hline \multirow[b]{4}{*}{ Sports activity type } & ctiv & after & atic & \\
\hline & \multicolumn{4}{|c|}{ Returning to sports activities } \\
\hline & \multicolumn{2}{|c|}{ Yes } & \multicolumn{2}{|c|}{ No } \\
\hline & $\mathrm{n}$ & $\%$ & $\mathrm{n}$ & $\%$ \\
\hline Competitive $(n=9)$ & 8 & 88.9 & 1 & 11.1 \\
\hline Recreational $(n=5)$ & 1 & 20.0 & 4 & 80.0 \\
\hline Total $(n=14)$ & 9 & 64.3 & 5 & 35.7 \\
\hline
\end{tabular}

$96.2 \pm 1.9$ (range, 92 to 98 ) in the postoperative period $(\mathrm{p}=0.001)$. The mean pre- and postoperative $\mathrm{K} / \mathrm{P}$ scores were $72.4 \pm 3.1$ (range, 68 to 78 ) and $95.3 \pm 2.2$ (range, 92 to 98$)$, respectively $(p=0.001)$. The mean preoperative VAS score was $2.4 \pm 0.9$ (range, 1 to 4 ), and showed an improvement to $0.6 \pm 0.5$ (range, 0 to 1 ) in the postoperative period $(\mathrm{p}=0.001)$ (Table II).

Nine $(64.3 \%)$ patients returned to sports activities after surgery. The mean time until return to sports was $9 \pm 2.1$ (range, 6 to 12) months. Five of the patients were interested in recreational sports and nine were interested in competitive sports. While eight $(88.9 \%)$ of nine patients who did competitive sports returned to sports during follow-up, one (20.0\%) of five patients who did recreational sports were able to return to sports. While nine of $14(64.3 \%)$ patients returned to sports in total, this rate was quite high in the group engaged in competitive sports $(88.9 \%)$ (Table III). None of the patients had major complications. One patient exhibited superficial peroneal nerve paresthesia treated with conservative therapy. One patient had stiffness in the ankle treated with rehabilitation. None of the patients experienced wound problems or infections associated with surgery.

\section{DISCUSSION}

Arthroscopic lateral ankle ligament reconstruction using soft anchors with the arthroscopic MBT was found to be a reliable, safe and effective technique, when the outcomes were assessed at a minimum one-year follow-up, which is the most important finding obtained in this study. In addition, it should be noted that this minimally invasive procedure yields a high frequency of return to sports activities.

Although there were no additional lesions other than talar OCL detected in three cases in our study, CAI is a chronic disorder, indeed, that manifests with secondary coexisting lesions in the joint and leads to functional problems in patients, and MRI fails to suffice in visualizing these pathologies in some cases. ${ }^{[13,24]}$ Open MBT is accepted as the gold-standard procedure in the surgical treatment of CAI, with several studies reporting good to excellent clinical outcomes. ${ }^{[25,26]}$ However, considering the relevant literature, Lee et al. ${ }^{[27]}$ investigated coexisting intraarticular pathologies in 28 patients diagnosed with CAI and reported the presence of additional pathologies in 22 patients and Ferkel and Chams ${ }^{[19]}$ reported that the rate of intraarticular pathologies was $95 \%$ in a case series including 21 patients. In this context, arthroscopic MBT, which was the preferred method in this study, satisfies the need for evaluation and treatment of intraarticular structures and enables anatomic ligament reconstruction with the additional advantage of shorter recovery. Therefore, arthroscopic MBT emerged as a commonly preferred procedure in the treatment of patients with CAI, particularly when additional lesions are suspected. ${ }^{[28,29]}$

There are numerous studies in the literature on arthroscopic MBT. Considering the clinical outcomes of the technique, in a study by Corte-Real and Moreira, ${ }^{[30]}$ the mean postoperative AOFAS score was reported to be 94.4 among 31 patients followed for 25 months. In another study by Nery et al., ${ }^{[21]}$ the mean AOFAS score was reported to be 90 after a 10-year long-term follow-up in a case series of 38 patients. In the present case series of 14 patients, the mean AOFAS score improved from 74 to 96.21 between the pre- and postoperative period. In this respect, the present study has obtained successful results with arthroscopic MBT, similar to previous publications.

It is possible to speculate that the greatest technical challenge in arthroscopic MBT is the difficulty of arranging the anchor positions, since the distal fibula is a relatively small structure in the mediolateral plane. Implants that are easy to apply and provide effective results are necessary, 
as large-profile anchors pose a risk of damage to the bone. ${ }^{[31,32]}$ Additionally, it has been reported that biodegradable implants have problems ranging from premature degradation to instantaneous breakage. ${ }^{[33,34]}$ In the present study, we used soft anchors, which are easy to apply and have shown to have biomechanically superior properties. ${ }^{[34]}$ Similar studies have reported the use of two 1.4-mm soft anchors for lateral ligament reconstruction; ${ }^{[34]}$ however, we obtained similar reconstruction strength to the double-anchor method, since the single 2.9-mm soft anchor we employed was equipped with four threads. Therefore, this approach eliminated the necessity of identifying two anchor deployment positions and also reduced the cost of surgery.

According to the literature comparing singleor double-suture anchor use in ATFL repair, double-suture anchor use was reported to yield higher AOFAS and K/P scores and a high frequency of return to sports activities. ${ }^{[35]}$ Based on our study results, it is possible to conclude that the use of a single soft anchor for arthroscopic MBT in the present study may lead to similarly high AOFAS and K/P scores, as well as low VAS scores. ${ }^{[36]}$

Although the superiority of different techniques to each other was not investigated in our study, some previous studies compared the results of open technique and arthroscopic surgery. In randomizedcontrolled study in which similar scores were used to our study and the results of open MBT and arthroscopic MBT were compared, Yeo et al. ${ }^{[37]}$ found that VAS, AOFAS, and Karlsson scores were significantly improved at six weeks, six months, and 12 months in both groups. They also reported that there was no significant difference between techniques in terms of scores and complication rates. ${ }^{[37]}$ On the other hand, it has been reported that arthroscopic MBT has higher complication rates compared to open techniques, and that the majority of these complications result from the use of suture anchors. ${ }^{[23,38]}$ Therefore, bone tunnel techniques have been developed to replace anchor use. ${ }^{[38]}$ However, soft anchor use led to low complication rates in the literature $^{[28]}$ and bone tunnel techniques were not superior to the suture anchor technique from the biomechanical aspect. ${ }^{[39]}$ In a recent study, although there were no complications in either group, it was reported that the VAS score was higher in the open surgery group, compared to the arthroscopic surgery group. ${ }^{[40]}$ In the present study, there were no permanent complications, except for one case with transient joint stiffness and one case who developed transient paresthesia. Based on these findings, our results seem to be among the successful results in the literature.

Despite the clinical improvements, however, it is difficult to suggest the same success rates in terms of return to sports. While the mean time until return to sports was $9 \pm 2.1$ months in our study, this period was shorter in previous studies. ${ }^{[1,42]}$ In addition, those who did competitive sports returned to sports more frequently than those who did recreational sports at the end of the follow-up ( $89 \%$ vs. $20 \%$, respectively) in our study. Although the mean AOFAS scores improved in both groups, this may be due to the fact that the patients in the recreational sports group have a lower motivation to return to sports and have more anxiety about experiencing trauma again.

Nonetheless, this study has some limitations. First, the sample size is relatively small with a retrospective study design. Second, postoperative talar tilt angles, which are expected to reduce after surgery, were not measured and MRI studies to evaluate intraarticular healing were not performed. Even so, functional results demonstrated significant improvements at postoperative assessments, and the number of patients that were able to return to sports activities in the short-term was high. Finally, the follow-up time can be considered to be short for the investigation of the functional scores.

In conclusion, arthroscopic MBT performed with soft anchors has successful short-term outcomes in the treatment of CAI. In addition to being a minimally invasive technique, MBT is a safe and reliable technique with low complication rates and significant improvements in functional scores. However, a low ratio of return to sports can be considered the failure of the technique. Further large-scale, prospective studies should be conducted to draw a more accurate conclusion.

\section{Declaration of conflicting interests}

The authors declared no conflicts of interest with respect to the authorship and/or publication of this article.

\section{Funding}

The authors received no financial support for the research and/or authorship of this article.

\section{REFERENCES}

1. Fong DT, Hong Y, Chan LK, Yung PS, Chan KM. A systematic review on ankle injury and ankle sprain in sports. Sports Med 2007;37:73-94.

2. Irgıt K, Topkar M. Sporcularda ayak bileği dış yan bağ yaralanmalarında güncel yaklaşımlar. TOTBID Dergisi 2018;17:1-11. 
3. Swenson DM, Yard EE, Fields SK, Comstock RD. Patterns of recurrent injuries among US high school athletes, 20052008. Am J Sports Med 2009;37:1586-93.

4. van Rijn RM, van Os AG, Bernsen RM, Luijsterburg PA, Koes BW, Bierma-Zeinstra SM. What is the clinical course of acute ankle sprains? A systematic literature review. Am J Med 2008;121:324-31.e6.

5. Pourkazemi F, Hiller CE, Raymond J, Nightingale EJ, Refshauge KM. Predictors of chronic ankle instability after an index lateral ankle sprain: A systematic review. J Sci Med Sport 2014;17:568-73.

6. Munn J, Sullivan SJ, Schneiders AG. Evidence of sensorimotor deficits in functional ankle instability: A systematic review with meta-analysis. J Sci Med Sport 2010;13:2-12.

7. Hubbard TJ, Kramer LC, Denegar CR, Hertel J. Contributing factors to chronic ankle instability. Foot Ankle Int 2007;28:343-54.

8. Hiller CE, Kilbreath SL, Refshauge KM. Chronic ankle instability: Evolution of the model. J Athl Train 2011;46:133-41.

9. Löfvenberg R, Kärrholm J, Lund B. The outcome of nonoperated patients with chronic lateral instability of the ankle: A 20-year follow-up study. Foot Ankle Int 1994;15:165-9.

10. Cottom JM, Rigby RB. The "all inside" arthroscopic Broström procedure: A prospective study of 40 consecutive patients. J Foot Ankle Surg 2013;52:568-74.

11. Bell SJ, Mologne TS, Sitler DF, Cox JS. Twenty-six-year results after Broström procedure for chronic lateral ankle instability. Am J Sports Med 2006;34:975-8.

12. Lee KT, Park YU, Kim JS, Kim JB, Kim KC, Kang SK. Longterm results after modified Brostrom procedure without calcaneofibular ligament reconstruction. Foot Ankle Int 2011;32:153-7.

13. Cha SD, Kim HS, Chung ST, Yoo JH, Park JH, Kim $\mathrm{JH}$, et al. Intra-articular lesions in chronic lateral ankle instability: Comparison of arthroscopy with magnetic resonance imaging findings. Clin Orthop Surg 2012;4:293-9.

14. Hua Y, Chen S, Li Y, Chen J, Li H. Combination of modified Broström procedure with ankle arthroscopy for chronic ankle instability accompanied by intra-articular symptoms. Arthroscopy 2010;26:524-8.

15. Hunt KJ, Githens M, Riley GM, Kim M, Gold GE. Foot and ankle injuries in sport: Imaging correlation with arthroscopic and surgical findings. Clin Sports Med 2013;32:525-57.

16. Joshy S, Abdulkadir U, Chaganti S, Sullivan B, Hariharan K. Accuracy of MRI scan in the diagnosis of ligamentous and chondral pathology in the ankle. Foot Ankle Surg 2010;16:78-80.

17. Maffulli N, Del Buono A, Maffulli GD, Oliva F, Testa V, Capasso G, et al. Isolated anterior talofibular ligament Broström repair for chronic lateral ankle instability: 9-year follow-up. Am J Sports Med 2013;41:858-64.

18. Cannon LB, Hackney RG. Anterior tibiotalar impingement associated with chronic ankle instability. J Foot Ankle Surg 2000;39:383-6.

19. Ferkel RD, Chams RN. Chronic lateral instability: Arthroscopic findings and long-term results. Foot Ankle Int 2007;28:24-31.
20. Corte-Real NM, Moreira RM. Arthroscopic repair of chronic lateral ankle instability. Foot Ankle Int 2009;30:213-7.

21. Nery C, Raduan F, Del Buono A, Asaumi ID, Cohen M, Maffulli N. Arthroscopic-assisted Broström-Gould for chronic ankle instability: A long-term follow-up. Am J Sports Med 2011;39:2381-8.

22. Kim ES, Lee KT, Park JS, Lee YK. Arthroscopic anterior talofibular ligament repair for chronic ankle instability with a suture anchor technique. Orthopedics 2011;34:273.

23. Wang J, Hua Y, Chen S, Li H, Zhang J, Li Y. Arthroscopic repair of lateral ankle ligament complex by suture anchor. Arthroscopy 2014;30:766-73.

24. Choi WJ, Lee JW, Han SH, Kim BS, Lee SK. Chronic lateral ankle instability: The effect of intra-articular lesions on clinical outcome. Am J Sports Med 2008;36:2167-72.

25. Cox JS. Surgical and nonsurgical treatment of acute ankle sprains. Clin Orthop Relat Res 1985;(198):118-26.

26. Gould N, Seligson D, Gassman J. Early and late repair of lateral ligament of the ankle. Foot Ankle 1980;1:84-9.

27. Lee J, Hamilton G, Ford L. Associated intra-articular ankle pathologies in patients with chronic lateral ankle instability: Arthroscopic findings at the time of lateral ankle reconstruction. Foot Ankle Spec 2011;4:284-9.

28. Cordier G, Lebecque J, Vega J, Dalmau-Pastor M. Arthroscopic ankle lateral ligament repair with biological augmentation gives excellent results in case of chronic ankle instability. Knee Surg Sports Traumatol Arthrosc 2020;28:108-15.

29. Molloy AP, Ajis A, Kazi H. The modified Broström-Gould procedure--early results using a newly described surgical technique. Foot Ankle Surg 2014;20:224-8.

30. Corte-Real NM, Moreira RM. Arthroscopic repair of chronic lateral ankle instability. Foot Ankle Int 2009;30:213-7.

31. Li X, Lin TJ, Busconi BD. Treatment of chronic lateral ankle instability: A modified Broström technique using three suture anchors. J Orthop Surg Res 2009;4:41.

32. Messer TM, Cummins CA, Ahn J, Kelikian AS. Outcome of the modified Broström procedure for chronic lateral ankle instability using suture anchors. Foot Ankle Int 2000;21:996-1003.

33. Nho SJ, Provencher MT, Seroyer ST, Romeo AA. Bioabsorbable anchors in glenohumeral shoulder surgery. Arthroscopy 2009;25:788-93.

34. Brown CA, Hurwit D, Behn A, Hunt KJ. Biomechanical comparison of an all-soft suture anchor with a modified Broström-Gould suture repair for lateral ligament reconstruction. Am J Sports Med 2014;42:417-22.

35. Li H, Hua Y, Li H, Chen S. Anterior talofibular ligament (ATFL) repair using two suture anchors produced better functional outcomes than using one suture anchor for the treatment of chronic lateral ankle instability. Knee Surg Sports Traumatol Arthrosc 2020;28:221-6.

36. Atik OŞ. What are the expectations of an editor from a scientific article? Jt Dis Relat Surg 2020;31:597-8.

37. Yeo ED, Lee KT, Sung IH, Lee SG, Lee YK. Comparison of all-inside arthroscopic and open techniques for the modified broström procedure for ankle instability. Foot Ankle Int 2016;37:1037-45.

38. Lui TH. Modified arthroscopic brostrom procedure with bone tunnels. Arthrosc Tech 2016;5:e775-e780. 
39. Giza E, Nathe R, Nathe T, Anderson M, Campanelli V. Strength of bone tunnel versus suture anchor and push-lock construct in Broström repair. Am J Sports Med 2012;40:1419-23.

40. Ulucakoy C, Kaptan AY, Eren TK, Eren A, Olmez SB, Ataoglu $\mathrm{MB}$, et al. Is arthroscopic surgery as successful as open approach in the treatment of lateral ankle instability? Arch Orthop Trauma Surg 2021. [Online ahead of print]
41. Lee K, Jegal H, Chung H, Park Y. Return to play after modified broström operation for chronic ankle instability in elite athletes. Clin Orthop Surg 2019;11:126-30.

42. White WJ, McCollum GA, Calder JD. Return to sport following acute lateral ligament repair of the ankle in professional athletes. Knee Surg Sports Traumatol Arthrosc 2016;24:1124-9. 